Бахновский Александр Викторович

кандидат юридических наук, доцент кафедры международного права Северо-Кавказского филиала Российского государственного университета правосудия

\section{МЕЖДУНАРОДНЫЙ ДОГОВОР КАК ИСТОЧНИК МЕЖДУНАРОДНОГО ЧАСТНОГО ПРАВА}

Аннотация:

В настоящей статье рассмотрены основания признания международного договора в качестве источника международного частного права. Проведен анализ различных подходов к доктрине международного частного права. Актуальность обсуждаемой тематики обоснована наличием противоположных научных позиций, содержащих мнение авторов о признании международных договоров источниками международного частного права и о недопустимости этого. При условии отказа от международного договора как источника международного частного права из числа регуляторов будет исключено колоссальное количество судебных актов, содержащих результаты толкования международных договоров. В рамках представленного исследования автор детально изучил деятельность международных и национальных судебных инстанций. Кроме того, сделаны необходимые пояснения относительно значимости роли судебного прецедента в урегулировании частноправовых отношений.

Ключевые слова:

международное право, международное частное право, коллизия, международный договор, прецедент, доктрина, частные правоотношения, судебная система.
Bakhnovsky Aleksandr Viktorovich

PhD in Law, Associate Professor, International Law Department,

North Caucasus branch of

Russian State University of Justice

\section{INTERNATIONAL TREATY \\ AS A SOURCE OF PRIVATE \\ INTERNATIONAL LAW}

\begin{abstract}
Summary:
The paper reviews the reasons to admit that the international treaty is a source of international private law. The research analyzes various approaches to reviewing the doctrine of private international law. The relevance of the study is determined by the problem of opposite scientific views which determine whether international treaties can be recognized as private international law sources or not. By rejecting this scientific approach, one could exclude a great number of judicial acts interpreting international treaties and resolving urgent practical issues. The author reviews Russian and international judicial institutions activity and clarifies the role of legal precedent in settling the private legal relationship.
\end{abstract}

Предложенный в 1834 г. термин «международное частное право» (далее - МЧП) и в настоящее время вызывает множество споров относительно допустимости и правильности применения. Изначально соотнесенный с коллизиями законов [1], он довольно быстро получил «прописку»в научной доктрине европейских государств и использовался наравне с категорией «коллизионное право». Авторы, исследующие особенности английского и американского подходов к построению коллизионно-правового регулирования, как правило, рассматриваемые понятия употребляли как синонимы, переводя дискуссию от одного к другому [2]. Указанный подход актуален и сегодня.

Мы склонны полагать, что рассмотрение вопроса об источниках международного частного права уместно начать с определения его предмета, что даст представление о совокупности правовых отношений, подпадающих под регулирование исследуемой отрасли права, и исключит вовлечение в орбиту научной работы ошибочные элементы.

Исследователи XIX в. указывали на основной принцип преодоления коллизий законов: выбранное к применению право должно быть «наиболее состоятельным и полезным» [3, S. 67]. Таким образом, первоначальное значение для уяснения предназначения международного частного права имеет его практическая востребованность для разрешения спорных (коллизионных) ситуаций.

По мнению коллектива авторов работы «Международное частное право», предметом МЧП являются частноправовые отношения, которые имеют в составе иностранный элемент [4]. Г.К. Дмитриева определяет предмет МЧП как исключительно частные отношения между физическими и юридическими лицами, которые внутри государства регулируются нормами частного права [5, с. 10-11].

В настоящее время подготовлено достаточное количество работ, раскрывающих проблематику источников международного частного права. При этом часть исследований ориентирована на теоретические концепции, часть - базируется на имевших место практических вопросах 
или ситуациях. Задачей данной работы является систематизация подходов о месте международных договоров в системе источников МЧП.

На основании ч. 4 ст. 15 Конституции Российской Федерации 1993 г. составной частью правовой системы считаются общепризнанные принципы и нормы международного права, а также международные договоры, участником которых является наше государство [6]. При этом Конституция России не называет себя законом - ввиду чего имеет высшую юридическую силу на всей территории страны. Следует сделать оговорку относительно частого именования Конституции «основным законом». Дело в том, что последняя версия Конституции РСФСР 1972 г. официально называлась «Конституция (основной закон) Российской Федерации» [7]. Конституция РФ 1993 г. в официальном наименовании уже не содержала словосочетание «основной закон», однако «автоматически» в доктрине конституционного права такой шаблон сохранился.

В соответствии со ст. 1186 Гражданского кодекса Российской Федерации международные договоры входят в круг источников, на основании которых определяется подлежащее применению право [8]. Анализируя положения указанной статьи, авторы постатейных комментариев к ГК РФ склонны полагать, что выбор применимого права может базироваться также на правилах международных договоров и обычаев, являющихся важнейшим источником МЧП [9].

Рассматривая место международного договора в системе источников МЧП, следует разграничить несколько устоявшихся подходов.

Согласно воззрениям представителей цивилистической школы, международные договоры являются неотъемлемой частью международного частного права [10]. Школа международников выделяет ведущую роль международного договора среди всех источников МЧП: «действительно, изучить международное частное право возможно исключительно через международный договор» [11, с. 21]. Так, В.Г. Храбсков полагает, что актуальное «международное частное право представляет собой совокупность международных договорных и обычных норм...» [12, с. 38].

Большинство исследователей склонны воспринимать МЧП как полисистемное явление [13, c. 54], что предопределяет его наполненность и международно-, и национально-правовым нормативным материалом. При более детальном изучении такого подхода необходимо уточнить, что особенности международного и национального уровней наполнения данной отрасли права каждый автор устанавливает самостоятельно и (часто) независимо от коллег.

Представители «практического корпуса» доктрины МЧП уделяют особое внимание опыту толкования международных договоров на уровне судебной системы Российской Федерации ввиду чего актуальным и значимым для настоящего исследования видится рассмотрение проблематики признания судебного прецедента в качестве источника национального права. Г.М. Вельяминов указывает, что национальная компонента охватывает и прецедентное право (в зависимости от правовой традиции конкретного государства) [14].

Верховный суд Российской Федерации (далее - ВС РФ) обладает правом давать разъяснения по проблемам судебной практики через постановления, выступающие актами официального толкования, в том числе по вопросам применения международных договоров [15]. В постановлениях ВС РФ упоминается термин «прецедент» (конкретно в словосочетании «прецедентная практика»), но применительно к деятельности Европейского суда по правам человека (далее ЕСПЧ), рассматривающего дела о нарушений положений Конвенции о защите прав человека и основных свобод от 04.11.1950 г. [16]. Так, при изучении вопроса о присуждении компенсации за нарушение права на судопроизводство в разумный срок суд в удовлетворении требований отказал, сославшись на прецедентную практику ЕСПЧ [17].

Практика деятельности арбитражных судов свидетельствует об устоявшемся подходе следования позициям вышестоящих судов при рассмотрении дел в первой и последующей инстанциях. Так, в ст. 170 Арбитражного процессуального кодекса Российской Федерации официально допускается указание в мотивировочной части решения ссылок на постановления Пленума ВС РФ и сохранившие силу постановления Пленума Высшего арбитражного суда РФ по вопросам судебной практики [18].

В результате официальное непризнание в качестве источника российского права судебного прецедента встречает серьезные контраргументы в содержании самих нормативных актов и сложившейся судебной практике. Рассматривая первопричину этого феномена, нужно признать состоятельность следующего объяснения: нижестоящие суды заинтересованы в том, чтобы их решения соответствовали позиции высших судебных инстанций, что исключит возможность их отмены [19].

Н.Ю. Ерпылева указывает, что международное частное право является комплексной правовой системой, включающей нормы внутригосударственного законодательства, международных договоров и обычаев [20]. В этой части с ней согласен В.В. Гаврилов, поясняя, что МЧП это «полисистемный комплекс, состоящий из норм как национального, так и международного права» [21, с. 13]. 
Довольно часто позиция авторов о восприятии или невосприятии международного договора в качестве источника международного частного права раскрывается в рамках изучения конкретной проблематики частных правоотношений. Например, рассмотрение вопроса содержания автономии воли сторон как принципа международного частного права сопровождается указанием на его закрепление в Гаагской конвенции о праве, применимом к агентским соглашениям (1978 г.) (Россия не участвует) [22], Гаагской конвенции о праве, применимом к договорам международной купли-продажи товаров (1986 г.) [23], и иных документах [24, с. 102]. Тем самым подтверждается довод о восприятии международного договора в качестве источника международного частного права.

Иногда свою позицию исследователи излагают с помощью метода исключения. В частности, Н.В. Афоничкина [25], анализируя возможность избрания сторонами-участниками внешнеэкономической сделки в качестве источника обязательства международного договора, считает несправедливым не принимать международный договор в качестве источника МЧП; это заимствованный международным частным правом источник. Такой поход, безоговорочно признающий источником международного частного права международный договор, полностью соответствует взглядам А.Н. Ошенкова [26, с. 143].

Римская конвенция о праве, применимом к договорным обязательствам (1980 г.) [27], признается К.М. Шмиттгоффр в качестве источника МЧП как высказанное специалистами мнение о современном понимании коллизионного права [28, с. 588]. Указанный документ также считает источником Б.Р. Карабельников [29].

Анализ статьи 1 Римской конвенции 1980 г. позволяет определить область применения ее положений: к договорным обязательствам в любой ситуации, связанной с выбором законов разных государств (The rules of this Convention shall apply to contractual obligations in any situation involving a choice between the laws of different countries). Статья 4 посвящена правилам выбора применимого права, в том числе с возможностью выбора права государства, с которым контракт обеспечивает наиболее тесную связь.

М.П. Бардина [30], определяя круг источников частноправовых отношений, выделяет международные конвенции, среди которых центральное место принадлежит Венской конвенции о договорах международной купли-продажи товаров 1980 г.

Довольно продуктивными видятся взгляды авторов, рассматривающих проблематику источников международного частного права через практическую плоскость. Например, Ю.Н. Андреев признает международный коммерческий арбитраж важнейшим институтом МЧП, а основным источником фрункционирования и деятельности указанной структуры, по мнению автора, являются международные договоры и внутригосударственное (национальное) законодательство [31].

Однако существует и противоположная позиция. Некоторые исследователи отрицают международные соглашения как источники МЧП и поддерживают тезис о том, что это юридические факты, порождающие международные обязательственные отношения между самими государствами [32, с. 29].

На основании изученных подходов и содержания международных нормативных актов мы считаем обоснованным подход большинства авторов, воспринимающих международный договор в качестве источника международного частного права, «приобретающего все большее значение» [33].

\section{Ссылки:}

1. Story J. Commentaries on the Conflict of Laws, Foreign and Domestic, in Regard to Contracts, Rights, and Remedies, and Especially in Regard to Marriages, Divorces, Wills, Successions, and Judgments. New Jersey, 1834. 557 p.

2. Lorenzen E.G. Story's Commentaries on the Conflict of Laws - One Hundred Years After [Электронный ресурс] // Faculty Scholarship Series. 1934. Paper 4589. URL: http://digitalcommons.law.yale.edu/fss papers/4589 (дата обращения: 06.06.2018)

3. Neumeyer K. Die Gemeinrechtliche Entwickelung des Internationalen Privat-und Strafrechts bis Bartolus. Munchen; Berlin; Leipzig, 1916. $152 \mathrm{~S}$.

4. Международное частное право : учебник / П.Б. Айтов, А.М. Белялова, Е.А. Бородина и др. ; под ред. Р.А. Курбанова, А.С. Лалетиной. М., 2015. 216 с.

5. Международное частное право : учебник / отв. ред. Г.К. Дмитриева. М., 2004

6. Конституция Российской Федерации : принята всенародным голосованием 12 дек. 1993 г. // Собрание законодательства РФ. 2014. № 31. Ст. 4398 .

7. Конституция (Основной Закон) Российской Федерации - России : принята ВС РСФСР 12 апр. 1978 г. : введен в действие Декларацией ВС РСФСР от 12 апр. 1978 в порядке, установленном законом РСФСР от 12 апр. 1978 г. : утратила силу в связи с принятием Конституции РФ от 12 дек. 1993 г. // Ведомости ВС РСФСР. 1978. № 15. Ст. 407.

8. Гражданский кодекс Российской Федерации от 26 нояб. 2001 г. № 146-Ф3 : в ред. от 28 марта 2017 г. Ч. 3 // Собрание законодательства РФ. 2001. № 49. Ст. 4552.

9. Ершов В.А., Сутягин А.В., Кайль А.Н. Постатейный комментарий к Гражданскому кодексу Российской Федерации [Электронный ресурс]. Доступ из справ.-правовой системы «КонсультантПлюс».

10. Марышева Н.И., Лазарева Т.П., Власова Н.В. Цивилистическая концепция международного частного права // Журнал российского права. 2015. № 10. С. 57-66. 
11. Крылов С.Б. Международное частное право. М., 1930.

12. Храбсков В.Г. Международное частное право в системе общего международного права // Известия вузов. Правоведение. 1982. № 6. С. 34-38.

13. Нешатаева Т.Н. К вопросу о правовых системах, регулирующих международные отношения // Российский ежегодник международного права. 1993-1994. СПб., 1995. С. 47-63.

14. Вельяминов Г.М. Международное право: опыты. М., 2015. 1006 с.

15. О применении судами общей юрисдикции общепризнанных принципов и норм международного права и международных договоров Российской Федерации : постановление Пленума Верховного суда РФ от 10 окт. 2003 г. № 5 : в ред. от 5 марта 2013 г. // Российская газета. 2003. 2 дек.

16. Конвенция о защите прав человека и основных свобод : заключена в г. Риме 4 нояб. 1950 г. // Собрание законодательства РФ. 2001. № 2. Ст. 163.

17. Решение Верховного суда РФ от 28 апр. 2016 г. по делу № АКПИ16-330 [Электронный ресурс]. Доступ из справ.правовой системы «КонсультантПлюс».

18. О введении в действие Арбитражного процессуального кодекса Российской Федерации : федер. закон от 24 июля 2002 г. № 96-Ф3 // Российская газета. 2002. 27 июля.

19. Тарабан Н.А. Правовая природа судебного прецедента в России и его место в национальной правовой системе // Мировой судья. 2014. № 11. С. 29-33.

20. Ерпылева Н.Ю. Понятие, предмет, система и источники МЧП // Международное публичное и частное право. 2002. № 1. C. 18-29.

21. Гаврилов В.В. Международное частное право : учебное пособие. Владивосток, 1997.

22. Конвенция о праве, применимом к агентским соглашениям : заключена в г. Гааге 14 марта 1978 г. [Электронный ресурс]. Доступ из справ.-правовой системы «КонсультантПлюс».

23. Конвенция о праве, применимом к договорам международной купли-продажи товаров : заключена в г. Гааге 22 дек. 1986 г : документ не вступил в силу // Розенберг М.Г. Контракт международной купли-продажи. Современная практика заключения. Разрешение споров. М., 1996. С. 209-220.

24. Гражданский кодекс РФ. Международное частное право. Постатейный комментарий к разделу VI / под ред. П.В. Крашенинникова. М., 2014.

25. Афоничкина Н.В. К вопросу о системном подходе в исследовании проблемы реализации права при взаимодействии международного публичного, международного частного и внутригосударственного права // Международный правопорядок в современном мире и роль России в его укреплении : материалы международной научно-практической конференции, посвященной 90-летию профессора Д.И. Фельдмана / А. Абай, А.Х. Абашидзе, А.И. Абдуллин и др. ; редакционная коллегия: И.А. Тарханов и др. М., 2014. 527 с.

26. Ошенков А.Н. Регулирование инвестиционных соглашений: проблемы отраслевой принадлежности и применимого права // Московский журнал международного права. 2000. № 2. С. 140-149.

27. Конвенция о праве, применимом к договорным обязательствам : заключена в г. Риме 19 июня 1980 г. [Электронный ресурс]. Доступ из справ.-правовой системы «КонсультантПлюс».

28. Schmitthoff C.M. Conflict of Law Relation to Letters of Credit an English Perspective in Select Essays on International Trade Law / ed. by Chia Jui Chang. Dordrecht, 1988.

29. Карабельников Б.Р. Подход российского законодательства и судебной практики к оговорке о публичном порядке // Международное публичное и частное право. 2005. № 5.

30. Бардина М.П. Государственное регулирование внешнеторговой деятельности и внешнеторговые контракты // Международное публичное и частное право. 2005. № 6.

31. Андреев Ю.Н. Механизм гражданско-правовой защиты. М., 2010. 464 с.

32. Экспортно-импортные операции. Правовое регулирование / под ред. В.С. Позднякова. М., 1970.

33. Вознесенская Н.Н. Роль сравнительного правоведения при разработке и применении международного частного права // Закон. 2013. № 6. С. 112-122.

\section{References:}

Afonichkina, NV, Abay, A, Abashidze, AKh, Abdullin, Al (et al.), Tarkhanov, IA (et al). (eds.) 2014, 'Concerning the system approach to studying the law enforcement problem in the interaction of public international, private international and domestic law', Mezhdunarodnyy pravoporyadok v sovremennom mire i rol' Rossii v yego ukreplenii: materialy mezhdunarodnoy nauchnoprakticheskoy konferentsii, posvyashchennoy 90-letiyu professora D.I. Fel'dmana, Moscow, 527 p., (in Russian).

Andreev, YuN 2010, Mechanism of civil protection, Moscow, 464 p., (in Russian).

Aytov, PB, Belyalova, AM, Borodina (et al.), EA, Kurbanov, RA \& Laletina, AS (eds.) 2015, Private international law, textbook, Moscow, 216 p., (in Russian).

Bardina, MP 2005, 'State regulation of foreign trade activities and foreign trade contracts', Mezhdunarodnoye publichnoye $i$ chastnoye parvo, No. 6, (in Russian).

Dmitrieva, GK (ed.) 2004, Private international law, textbook, Moscow, (in Russian).

Erpyleva, NYu 2002, 'Concept, subject, system and sources of private international law', Mezhdunarodnoye publichnoye $i$ chastnoye pravo, No. 1, pp. 18-29, (in Russian).

Gavrilov, VV 1997, Private international law, manual, Vladivostok, (in Russian).

Karabelnikov, BR 2005, 'Approach of the Russian legislation and law case related to the public order reservation', Mezhdunarodnoye publichnoye i chastnoye parvo, No. 5, (in Russian).

Khrabskov, VG 1982, 'Private international law in the system of general international law', Izvestiya vuzov. Pravovedeniye, No. 6, pp. 34-38, (in Russian).

Krasheninnikov, PV (ed.) 2014, The Civil Code of the Russian Federation. Private international law. A paragraph-by-paragraph analysis to the section 6, Moscow, (in Russian).

Krylov, SB 1930, Private international law, Moscow, (in Russian).

Lorenzen, EG 1934, 'Story's Commentaries on the Conflict of Laws - One Hundred Years After', Faculty Scholarship Series, paper 4589, viewed 06 June 2018, <http://digitalcommons.law.yale.edu/fss papers/4589>

Marysheva, NI, Lazareva, TP \& Vlasova, NV 2015, 'The civilizational concept of private international law', Zhurnal rossiyskogo prava, No. 10, pp. 57-66, (in Russian).

Neshataeva, TN 1995, 'Concerning the legal systems regulating international relations', Rossiyskiy yezhegodnik mezhdunarodnogo prava. 1993-1994, St. Petersburg, pp. 47-63, (in Russian). 
Neumeyer, K 1916, Die Gemeinrechtliche Entwickelung des Internationalen Privat-und Strafrechts bis Bartolus, Munchen, Berlin, Leipzig, 152 S., (in German).

Oshenkov, AN 2000, 'Regulation of investment agreements: problems of industry and applicable law', Moskovskiy zhurnal mezhdunarodnogo prava, No. 2, pp. 140-149, (in Russian).

Pozdnyakov, VS (ed.) 1970, Export-import operations. Legal regulation, Moscow, (in Russian).

Rosenberg, MG 1996, 'Convention on the law applicable to contracts for the international sale of goods: concluded in the Hague on 22 December 1986: the document did not enter into force', Kontrakt mezhdunarodnoy kupli-prodazhi. Sovremennaya praktika zaklyucheniya. Razresheniye sporov, Moscow, pp. 209-220, (in Russian).

Schmitthoff, CM \& Chia Jui Chang (ed.) 1988, Conflict of Law Relation to Letters of Credit an English Perspective in Select Essays on International Trade Law, Dordrecht.

Story, J 1834, Commentaries on the Conflict of Laws, Foreign and Domestic, in Regard to Contracts, Rights, and Remedies, and Especially in Regard to Marriages, Divorces, Wills, Successions, and Judgments, New Jersey, 557 p.

Taraban, NA 2014, 'The legal nature of the legal precedent in Russia and its place in the national legal system', Mirovoy sud'ya, No. 11, pp. 29-33, (in Russian).

Velyaminov, GM 2015, International law: experiments, Moscow, 1006 p., (in Russian).

Voznesenskaya, NN 2013, 'The role of comparative law in the development and application of private international law', Zakon, No. 6. pp. 112-122, (in Russian). 